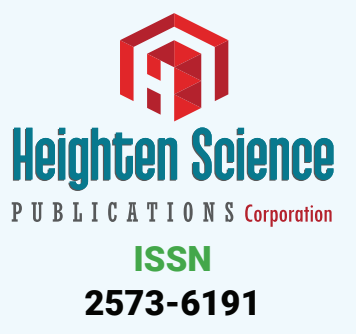

*Address for Correspondence: Renato Marano, Ph.D. in Ciências da Cirurgia, Faculdade de Ciências Médicas da Universidade Estadual de Campinas, FCM-UNICAMP, Brazil, Tel: 30977712/995747712; Email: renato@renatomarano.com.br; contato@renatomarano.com.br

Submitted: 06 April 2017

Approved: 25 April 2017

Published: 26 April 2017

Copyright: @ 2017 Renato Marano, et al. This is an open access article distributed under the Creative Commons Attribution License, which permits unrestricted use, distribution, and reproduction in any medium, provided the original work is properly cited.

\title{
External Root Resorption associated with Impacted Third Molars: A Case Report
}

\author{
Gabriela Mayrink, Paula Ramos Ballista, Laisa Kinderlly, Stella \\ Araujo and Renato Marano* \\ Ciências da Cirurgia, Faculdade de Ciências Médicas da Universidade Estadual de Campinas, \\ FCM-UNICAMP, Brazil
}

\section{ABSTRACT}

The indications for impacted third molar extraction include the prevention of dental reabsorption on the adjacent tooth. Resorption can be classified as physiological (when deciduous teeth are exfoliated) or pathological (when caused by injury or irritation to the periodontal ligament). Many causes can trigger external root resorption (ERR), the most common cause of which is orthodontic forces. The most common cases of ERR involve impacted third molars which, due to the lack of space for their eruption, generate a greater chance of ERR on the distal portion of the second molar. This pathology is becoming progressively more frequent in clinical dental care. Periapical and panoramic radiographs are used to aid in diagnosis, as is cone beam computed tomography. In cone beam computed tomography scans, radiolucent areas with irregular gaps are detected; these gaps represent a significant loss of dental material. The objectives of this article were to report a case of second molar resorption triggered by an impacted third molar and to perform a review of the literature on the causes of external root resorption. Ideally, this information will aid dental clinicians (and orthodontists in particular) in understanding the features of this pathology so that they may recommend preventive third molar extraction when necessary.

\section{INTRODUCTION}

Lower third molars are frequently impacted due to the lack of space between the distal portion of the second molar and the anterior border of the ascending ramus of the mandible. Impacted teeth may be asymptomatic or may be associated with pathologies such as caries, pericoronitis, odontogenic tumors and cysts, and root resorptions of the adjacent tooth [1,2]. External root resorption (ERR) of the second molar is a pathological process which occurs on the surface of the root and which is induced by local inflammation or mechanical stress [2].

According to Consolaro [3], pathological tooth resorptions may occur through one of two mechanisms: inflammation or replacement. Inflammation occurs when the mineralized surface of the root is exposed and the cementoblasts are removed from the surface. Thus, the closely located bone cells enable root resorption, albeit temporarily. Resorption resulting from replacement occurs after trauma to the teeth in which dentoalveolar ankylosis is induced. In this case, bone remodeling also involves the mineralized dental tissues, which are gradually and inevitably reabsorbed and replaced by bone [3].

The primary identification of ERR relies on radiographic exams; however, periapical or panoramic radiographs are not the most adequate method for determining 
abnormalities in the scan. Cone beam computed tomography provides a more precise view of the dental structures, resulting in a more exact diagnosis [1].

The objectives of this article are to report a case of external root resorption of the second molar associated with the presence of an impacted third molar and to provide a review of the literature on the subject.

\section{CLINICAL CASE}

A male patient referred to as YM, 16 years of age, had been diagnosed with four impacted third molars at a routine orthodontic exam. At that time, he was instructed by the orthodontist to seek the preventive extraction of the teeth, as they were in an unfavorable position and there was no space in the patient's arch for proper eruption. The pacient signed de informed consent form.

It was not until 20 years of age, when he began an airline pilot training program, that the patient sought medical care from an oral and maxillofacial surgeon.

A panoramic radiograph was obtained. Though the impaction was asymptomatic, tooth 38 was horizontal and exhibited mesial bone loss. A radiolucent image was observed on the distal portion of tooth 37 (Figure 1).

Cone beam computed tomography revealed external root resorption of tooth 37 (Figure 2). The patient was evaluated by endodontic specialists who indicated extraction of the second molar due to the impossibility of endodontic treatment (the limited amount of root remaining), as this would generate perforation of the root canal. Mere observation of the tooth was not a viable option: because the patient was studying to be a pilot, the possibility of barodontalgia would be high and frequent.

For this reason, teeth 37 and 38 were extracted in a single session under local anesthesia with the aid of a high-speed dental hand piece and refrigeration with $0.9 \%$ saline solution. The resorption of tooth 37 was clinically evident after extraction (Figure 3a,b).

The surgery was performed with no intraoperative complications. Three months after the excision, an osseo integrated dental implant was installed in the region of tooth 37 . The patient is currently rehabilitated and has reported no complications or complaints.

\section{DISCUSSION}

Impacted teeth are those which cannot reach their normal functional position. This

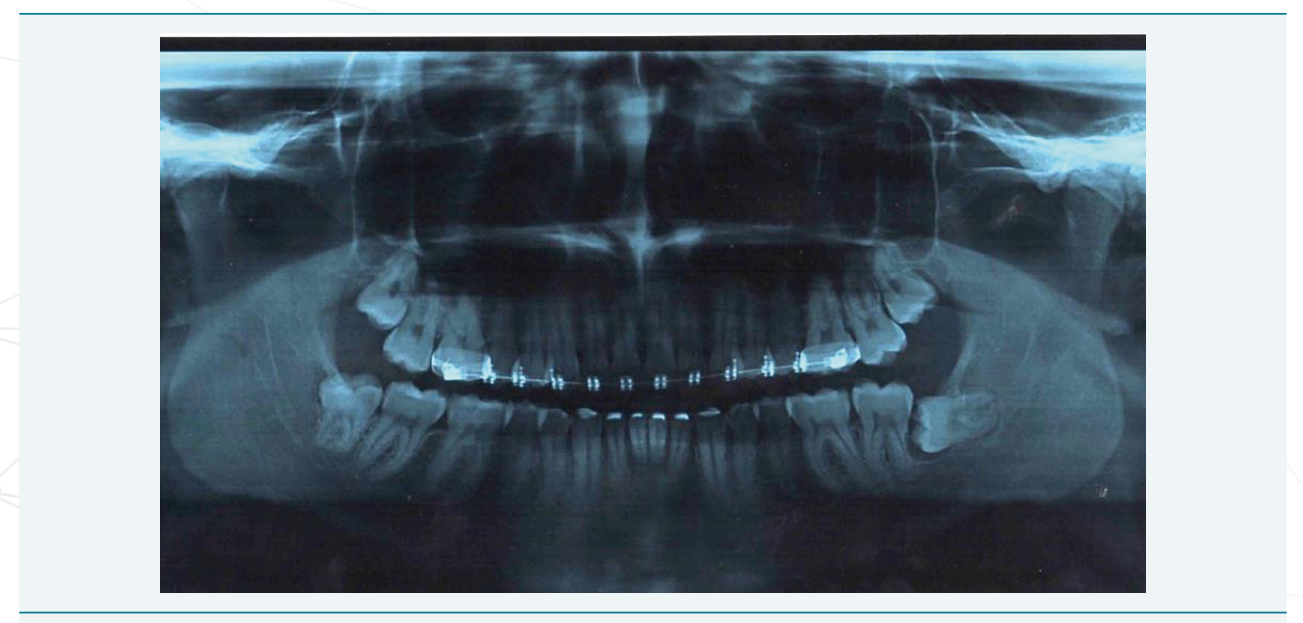

Figure 1: Panoramic radiograph. A radiolucent image was observed on the distal portion of tooth 37. 


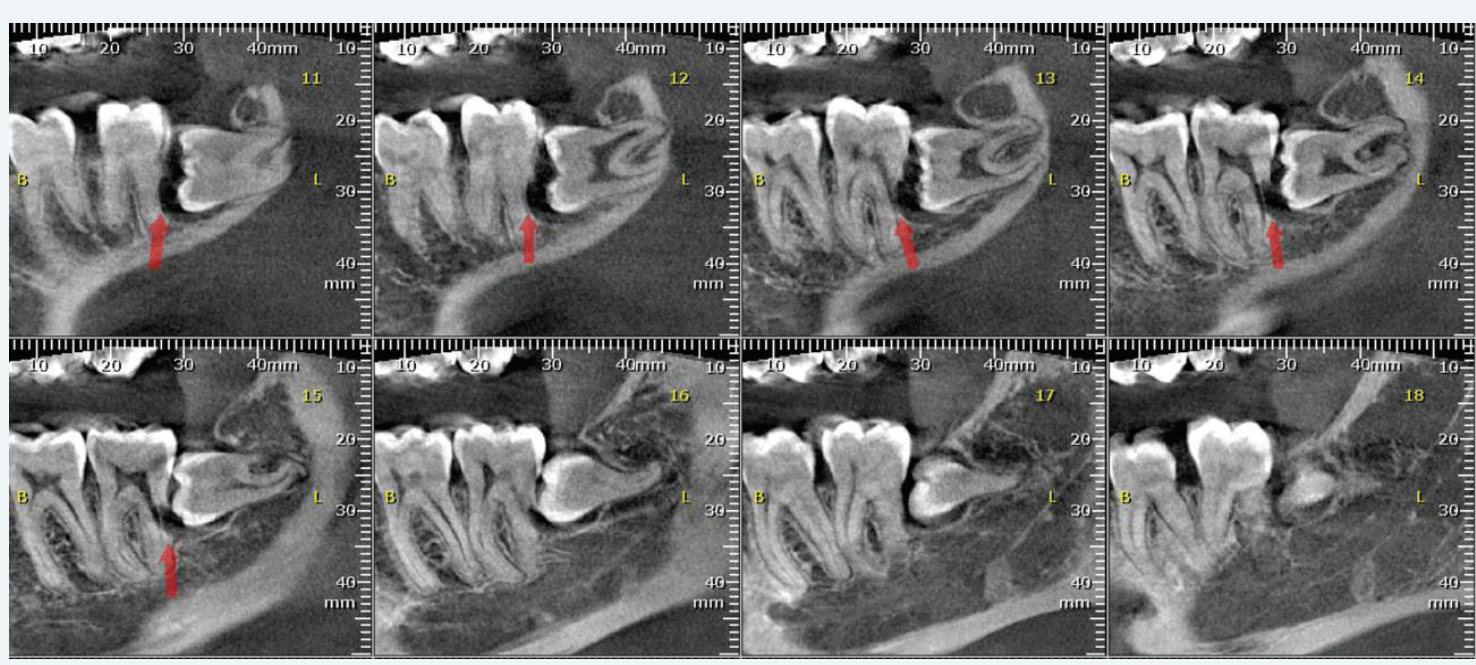

Figure 2a: Cone beam computed tomography revealed external root resorption of tooth 37 .

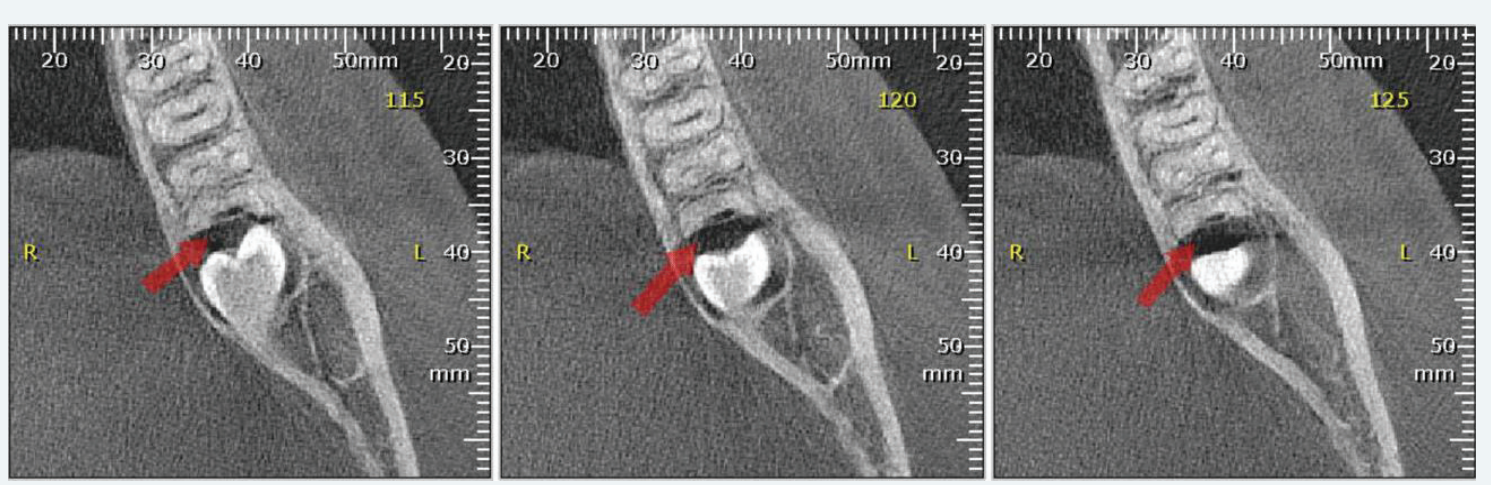

Figure $2 \mathrm{~b}$ : Cone beam computed tomography revealed external root resorption of tooth 37 .

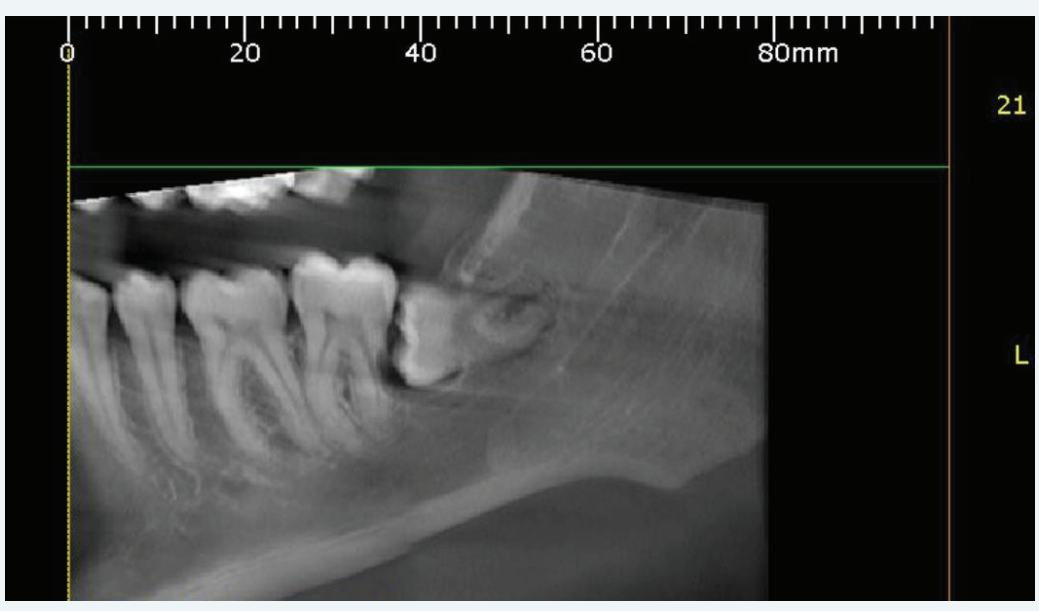

Figure 2c: Cone beam computed tomography revealed external root resorption of tooth 37 .

pathology frequently occurs in the case of the third molar. The etiology of impaction has been theorized to be the gradual evolutionary reduction in the size of the jaw due to the loss of stimulation of bone growth resulting from the modern human diet, which requires relatively little effort in mastication [2].

Third molar extraction may be indicated as a preventive measure due to the 


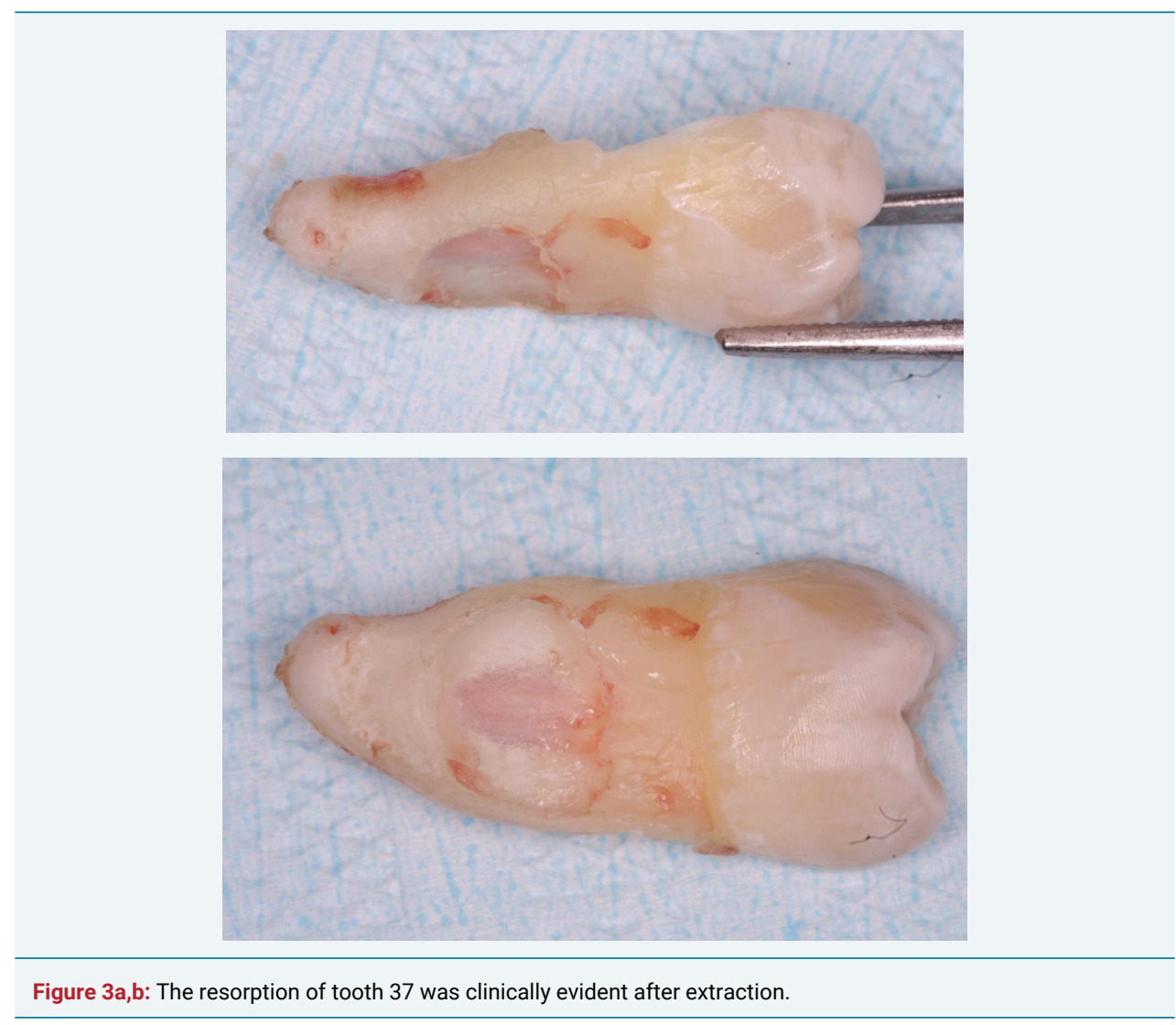

possibility of serious consequences of acute pericoronitis and other pathological conditions such as caries, odontogenic cysts, and root resorption [4-6].

It is believed that the early removal of third molars is necessary to avoid crowding of the lower incisors; however, this indication is uncertain [7]. In a study analyzing radiographs, Nemcovsky et al. (1996) evaluated the incidence of second molar root resorptions caused by third molars. The authors concluded that a higher percentage of ERR cases were associated with third molars with mesial inclination greater than 60 degrees, and the number of cases increased as patient age increased [8].

In 2015, Oenning et al. [9] performed a retrospective study to analyze CT scans from patients with horizontal or mesioangular third molars that were in contact with the second molar. They analyzed the frequency of ERR in the adjacent tooth. The authors concluded that both mesioangular and horizontal molars resulted substantial potential for second molar resorption, particularly in cases of Pell and Gregory Class A and Class $B$ third molars in patients 25 years of age and older. The authors suggested that, under these conditions, preventive extraction of the third molar should be indicated due to the high risk of second molar ERR.

In this case report, the patient was 20 years of age, and resorption of the second molar had already begun. Early extraction of the third molar may have prevented the loss of the second.

This resorption associated with impacted third molars occurs through the inflammatory root resorption of the second molar due to an obstruction of the blood vessels of the adjacent tooth. After the cause is eliminated, cellular stress in the area and the inflammatory process end. Osteoblasts and osteoclasts migrate to the root surface, and the $\mathrm{pH}$ returns to its normal levels. These changes enable the recolonization of new cementoblasts. In cases of bacteria in the pulp cavity, endodontic treatment is adequate for resolving inflammatory process. Another method of treatment is to spread 
the orthodontic force established in the region, which eliminates the inflammatory process [3].

The patient in question was an aspiring pilot. In this case, extraction of only the third molar would remove the mechanical stress on the second molar. However, mere observation was not a viable option in this case due to the moderate to severe degree of resorption. Endodontic treatment was impeded by the lack of viable space for endodontic instruments. Furthermore, the risk of barodontalgia is high in patients who frequently experience changes in air pressure, such as pilots.

Barodontalgia is defined as dental pain associated with changes in pressure. It affects $11.9 \%$ of divers and $11 \%$ of pilots, the latter of which experience barodontalgia at an average rate of 5 episodes with every 1,000 hours of flight. The most prevalent pathologies associated with pain during flight are dental restorations, caries without pulp involvement, pulp necrosis or periapical inflammation, vital pulp pathology, recent dental treatment, and barosinusitis. The intensity of pain in cases of has been found to vary from moderate (25\%) to intense (75\%) [10].

Though uncommon, this condition must be taken seriously, as it can put divers, pilots, and airline passengers' lives at risk. The World Dental Federation (FDI) recommends annual dental screenings for these professionals, as well as regular hygiene instruction from dentists familiar with each patient. In addition, patients should not dive or fly in unpressurized cabins for 24 hours after dental treatments involving anesthesia and for 7 days after surgical dental treatments $[10,11]$.

Higher education programs in the field of aeronautical sciences often require periodic dental consults of their students, as well as adequate oral hygiene and a dentist's report on their oral health. In light of these factors and in an attempt to avoid barodontalgia, the conduct chosen herein (at the patient's consent) was the extraction of the impacted tooth and the adjacent tooth with external root resorption.

\section{CONCLUSION}

External root resorption of the second molar may be avoided with preventive extraction of impacted third molars, particularly those in mesioangular or horizontal positions. Treatment varies according to the degree of resorption and the specific conditions of each patient.

\section{REFERENCES}

1. Lee YJ, Lee TY. External root resorption during orthodontic treatment in root- filled teeth and contralateral teeth with vital pulp: A clinical study of contributing factors. Am J Orthod Dentofacial Orthop. 2016; 149 84-91. Ref.: https://goo.gl/qb8uAd

2. Santosh P. Impacted Mandibular Third Molars: Review of Literature and a Proposal of a Combined Clinical and Radiological Classification. Ann Med Health Sci Res. 2015; 4: 229-234. Ref.: https://goo.gl/FTcJ80

3. Consolaro A. O conceito de reabsorções dentárias ou As reabsorções dentárias não são multifatoriais, nem complexas, controvertidas ou polêmicas! Dental Press J Orthod. 2011; 16: 1924. Ref.: https://goo.gl/IVhWH9

4. Lysell L, Rohlin M. A study of indications used for removal of the mandibular third molar. Int $\mathrm{J}$ Oral Maxillofac Surg. 1988; 17: 161-164. Ref.: https://goo.gl/jocsXr

5. Yamalık K, Bozkaya S. The predictivity of mandibular third molar position as a risk indicator for pericoronitis. Clin Oral Investig. 2008; 12: 9-14. Ref.: https://goo.gl//7AtbH

6. Camargo IB, Sobrinho JB, Andrade ESSA, Van Sickels JE. Correlational Study of Impacted and NonFunctional Lower Third Molar Position with Occurrence of Pathologies. Prog Orthod. 2016; 17: 1-9. Ref.: https://goo.gl/xqNwup

7. Bishara SE, Andreasen G. Third molars: A review. Am J Orthod. 1983; 83: 131-137. Ref.: https://goo.gl/mB0f7S 
8. Nemcovsky CE, Libfeld H, Zubery Y. Effect of non-erupted third molars on distal roots and supporting structures of approximal teeth. A radiographic survey of 202 cases. J Clin Periodontol. 1996; 23: 810-815. Ref.: https://goo.gl/YAF37c

9. Oenning AC, Melo SL, Groppo FC, Haiter-Neto F. Mesial inclination of impacted third molars and its propensity to stimulate external root resorption in second molars-a cone-beam computed tomographic evaluation. J Oral Maxillofac Surg. 2015; 73: 379-386. Ref.: https://goo.gl/xWzVbg

10. Zadik Y. Barodontalgia: what have we learned in the past decade? Oral Surg Oral Med Oral Pathol Oral Radiol Endod. 2010; 109: 65-69. Ref.: https://goo.gl/FivRxf

11. Robichaud, R., McNally, M.E. Barodontalgia as a Differential Diagnosis: Symptoms and Findings. J Can Dent Assoc. 2005; 71: 39-42. Ref.: https://goo.gl/1ITgk0 